\title{
CURSO SUPERIOR ESPECIAL PARA ASSENTAMENTOS DA REFORMA AGRÁRIA: AGRONOMIA COM ÊNFASE EM AGROECOLOGIA E SISTEMAS RURAIS SUSTENTÁVEIS, UMA PROPOSTA INCRA- PRONERA/UFSCAR
}

\author{
CURSO SUPERIOR PARA ASENTAMIENTOS DE LA REFORMA AGRARIA: \\ AGRONOMÍA CON ÉNFASIS EN AGROECOLOGÍA Y SISTEMAS RURALES \\ SUSTENTABLES, UNA PROPUESTA INCRA-PRONERA/UFSCAR
}

\section{SPECIAL COLLEGE COURSE FOR SETTLEMENTS FROM LAND REFORM: AGRONOMY WITH EMPHASIS ON AGROECOLOGY AND SUSTAINABLE RURAL SYSTEMS, AN INCRA-PRONERA/UFSCAR PROPOSAL.}

\author{
Marcelo Nivert Schlindwein ${ }^{1}$ \\ mnivert@ufscar.br \\ Fernando Nadal Junqueira Villela ${ }^{2}$ \\ fernando.villela@ufscar.br \\ Waldemar Marques ${ }^{3}$ \\ wmarques@ufscar.br \\ Manoel Baltasar Baptista Costa \\ baltasar@uol.com.br \\ Alice Helena Campos Pierson ${ }^{4}$ \\ apierson@ufscar.br \\ Farid Eid ${ }^{5}$ \\ farid@ufscar.br
}

Resumo: O presente documento é produto do trabalho desenvolvido por docentes e pesquisadores da Universidade Federal de São Carlos - UFSCar, representações técnicas do INCRA (Instituto Nacional de Colonização e Reforma Agrária) e dirigentes e assessores de quatro Movimentos Sociais do Campo no Estado de São Paulo (Federação dos Empregados Rurais Assalariados do Estado de São Paulo - FERAESP, Federação dos Trabalhadores da Agricultura Familiar do Estado de São Paulo - FAF, Movimento dos Trabalhadores Rurais Sem Terra do Estado de São Paulo - MST - SP, e Organização das Mulheres Assentadas e Quilombolas do Estado de São Paulo OMAQUESP). A partir de demanda apresentada pelo INCRA por um curso de

\footnotetext{
${ }^{1}$ Prof. Adjunto Campus Sorocaba - Universidade Federal de São Carlos

${ }^{2}$ Prof. Assistente Campus Sorocaba - Universidade Federal de São Carlos

${ }^{3}$ Coordenador Acadêmico e Professor Adjunto Campus Sorocaba - Universidade Federal de São Carlos

${ }^{4}$ Profa. Adjunta Campus São Carlos, Centro de Educação e Ciências Humanas - Departamento de Metodologia de Ensino - Universidade Federal de São Carlos

${ }^{5}$ Coord. GT Incra-Pronera/UFScar e Professor Adjunto Campus São Carlos - Centro de Ciências Exatas e de Tecnologia, Departamento de Engenharia da Produção - Universidade Federal de São Carlos
} 
agronomia voltado à formação de agricultores beneficiados pela Reforma Agrária, foi elaborada uma proposta de Curso de Agronomia com ênfase em Agroecologia e Sistemas Rurais Sustentáveis, em caráter temporário e regime especial. O curso, pautado nos pressupostos da agroecologia e da agricultura sustentável, foi iniciado em janeiro de 2009 na Escola Popular Rosa de Luxemburgo, município de Iaras, através da direção do Campus da UFSCar de Sorocaba.

Palavras-chave: PRONERA, Movimentos Sociais do Campo, Agronomia, Agroecologia, Sistemas Rurais Sustentáveis.

Resumen: El presente documento resulta de un trabajo desarrollado por profesores e investigadores de la Universidad Federal de São Carlos - UFSCAR, representaciones técnicas del INCRA (Instituto Nacional de Colonización y Reforma Agraria) y líderes y asesores de cuatro Movimientos Sociales Campesinos en el estado de São Paulo (Federación de los Empleados Rurales Asalariados del Estado de São Paulo FERAESP, Federación de los Trabajadores en Agricultura Familiar del Estado de São Paulo - FAF, Movimiento de los Trabajadores Rurales Sin Tierra del Estado de São Paulo - MST-SP, y Organización de Mujeres Asentadas y Quilombolas del Estado de São Paulo - OMAQUESP). Desde la demanda presentada por el INCRA para un curso de agronomía dirigido a la formación de agricultores beneficiados por la Reforma Agraria, fue planteado un Curso de Agronomía con énfasis en Agroecología y Sistemas Rurales Sostenibles, en carácter temporario y especial. El curso, basado en los conceptos de agroecología y de agricultura sustentable, fue iniciado en enero de 2009 en la Escola Popular Rosa de Luxemburgo 1 municipio de Iaras, SP, tras la dirección del campus de UFSCar de Sorocaba.

Palabras-llave: PRONERA, Movimientos Sociales Campesinos, Agronomía, Agroecología, Sistemas Rurales Sostenibles.

Abstract: The present document is a product of the work developed by teachers and researchers from Federal São Carlos University - UFSCAR, technical representations from INCRA (National Institute of Colonization and Land Reform) and leaders and assessors of four Social Land Movements in Sao Paulo State (Rural Wageworkers Federation of Sao Paulo State - FERAESP, Family Agriculture Workers Federation of Sao Paulo State - FAF, Landless Rural Workers Movement of Sao Paulo State - MSTSP, and Settled Women and Quilombolas Organization of Sao Paulo State OMAQUESP). From a demand presented by INCRA for a course of agronomics aimed at the formation of land workers benefited by Land Reform, a proposal was elaborate for an Agronomy Course with emphasis on Agroecology and Sustainable Rural Systems, with a temporary and special character. The course, based on principles of agroecology and sustainable land use, started in January 2009 at Escola Popular Rosa de Luxemburgo, in Iaras County, SP, through UFSCar Sorocaba campus management.

Key words: PRONERA, Social Land Movements, Agronomy, Agroecology, Sustainable Rural Systems 


\section{INTRODUÇÃO}

Com base na demanda apresentada pelo INCRA (Instituto Nacional de Colonização e Reforma Agrária) por um curso de agronomia voltado à formação de agricultores inclusos no programa nacional de Reforma Agrária, a partir de Seminário Universidade e Reforma Agrária (São Carlos - 30/06/2006), foi elaborada a proposta de um curso de Agronomia com ênfase em Agroecologia e Sistemas Rurais Sustentáveis. Este curso é produto do trabalho desenvolvido por grupo multidisciplinar e interinstitucional de docentes e pesquisadores da Universidade Federal de São Carlos UFSCar, INCRA e dirigentes e assessores de quatro Movimentos Sociais do Campo (Federação dos Empregados Rurais Assalariados do Estado de São Paulo - FERAESP, Federação dos Trabalhadores da Agricultura Familiar do Estado de São Paulo - FAF, Movimento dos Trabalhadores Rurais Sem Terra do Estado de São Paulo - MST - SP, através da Cooperativa Central de Reforma Agrária do Estado de São Paulo - CCA-SP, e Organização das Mulheres Assentadas e Quilombolas do Estado de São Paulo OMAQUESP).

O INCRA é responsável pela gestão do Programa Nacional de Educação na Reforma Agrária - PRONERA, o qual contempla o desenvolvimento de iniciativas no âmbito da Educação Superior, visando capacitar os agricultores assentados no país, nas esferas da educação e da produção agrícola, dentre outras. Nesse sentido esta instituição federal tem demandado o apoio das Universidades Públicas, e já está em execução uma iniciativa afim, assumida pela Universidade Estadual do Mato Grosso - UNEMAT.

A partir deste trabalho conjunto foi elaborada a presente proposta, em caráter temporário e regime especial. Temporário porque está previsto para atender uma turma apenas, sem o caráter de continuidade de oferta anual, que caracteriza os demais cursos ofertados pela universidade. Especial porque combina atividades presenciais em sala de aula e laboratório e atividades nos locais de trabalho e moradia nos assentamentos de reforma agrária e comunidades rurais.

As ações do Grupo de Trabalho (GT) deste projeto incluíram a realização de reuniões de trabalho nos três campi da UFSCar, discussões e elaboração de 
contribuições escritas pelos membros do GT, e consulta aos departamentos responsáveis por temáticas afins aos propósitos do curso, sobre possíveis colaborações e apoios à proposta.

O Grupo de Trabalho responsável pela elaboração do Projeto Pedagógico propôs que, após sua apreciação e aprovação pelas instâncias competentes, o curso iniciasse em janeiro de 2009, sendo a primeira etapa realizada na "Escola Popular Rosa de Luxemburgo, Iaras, SP. As etapas subseqüentes devem ocorrer prioritariamente no Campus da UFSCar de Sorocaba, dado o interesse e envolvimento de um número expressivo de docentes daquele campus com a proposta, e pela presença na região da Floresta Nacional (FLONA) Ipanema, localizada no Município de Iperó, com instalações adequadas à realização das atividades de ensino demandadas pela iniciativa - espaços para salas de aula, atividades práticas, alojamentos e refeitório.

Apenas algumas etapas do curso serão realizadas nos Campus de São Carlos e Araras, em função de alguns recursos e equipamentos laboratoriais específicos inexistentes no campus de Sorocaba.

Este curso foi concebido a partir de procedimentos pedagógicos na perspectiva da indissociabilidade entre as atividades cotidianas do ensino, pesquisa e extensão universitária. Este processo estará associado com a metodologia da alternância, que pressupõe diferentes estratégias de ensino-aprendizagem, compreendendo o ensino como a construção de conhecimento e a aprendizagem como o exercício educativo na formação da identidade.

A proposta deste curso de graduação (UFSCAR, 2008), com cinco anos de duração, está pautada nos pressupostos da agroecologia e da agricultura sustentável, sustentabilidade essa assumida em suas dimensões sócio-cultural, ecológica, energética e econômica.

A expectativa é que o curso propicie a formação de agrônomos com um perfil profissional que os habilite a analisar criticamente e a repensar as formas de interação da agricultura com a realidade em que esteja inserida, com ênfase no segmento da 
agricultura familiar camponesa, valorizando e contribuindo para a equidade na distribuição da renda, valorização das culturas locais e respeito ao meio ambiente. Poucos são os esforços na formação de profissionais com um conteúdo técnicocientífico que trabalhem com a perspectiva da construção de um novo modelo de desenvolvimento agrícola sustentável.

Um dos conceitos que tomou conta dos debates ambientalistas foi o conceito de Desenvolvimento Sustentável. SMITH e ENGER, (1995) criticam o termo sustentável, por ser ambíguo, e com muitas interpretações. Crescimento sustentável é, em termos, uma contradição, pois nada em física cresce indefinidamente (tirando a teoria do universo em expansão indefinida). E o termo sustentável seria apenas utilizado para recursos sustentáveis, pois estes podem se renovar. Outra contradição teórica seria a que se há desenvolvimento de algo, a transformação e modificação, portanto não haveria sustentabilidade. Apesar destes problemas conceituais a idéia de que devemos caminhar para processos que mantenham a integridade dos sistemas naturais da melhor maneira possível é bastante bem-vinda e serve como base filosófica do ambientalismo (SCHLINDWEIN, 2009).

O definir Desenvolvimento Sustentável não é simples, pois correntes ideológicas e filosóficas traduzem esta expressão de maneiras distintas. Se pensarmos em termos restritos aos recursos naturais e a diversidade da vida a Sustentabilidade pode ser definida como a capacidade da terra da sustentar e manter da vida e persistir como um sistema. Para um ecólogo a Sustentabilidade está diretamente relacionada ao componente de complexidade dos sistemas e da diversidade Natural. Um agroecossistema sustentável deveria portanto manter sua capacidade de se auto reproduzir e manter as espécies que o compõem, além de conservar os nutrientes necessários para seu funcionamento. O conceito de desenvolvimento sustentável envolve deve abranger componentes Ecológicos, Sociais e Econômicos. O seu discurso inclui a reconciliação dialética entre o meio ambiente e o desenvolvimento econômico (LEFF, , 2002).

A partir da década de 70 cada vez mais os governos esbarram em um problema intricado no âmbito das questões ambientais. Várias práticas de exploração passaram a 
ter efeitos nocivos, afetando drasticamente as populações em sua qualidade de vida e causando um ônus para estes governos. A falta de água potável, a contaminação ambiental e os problemas de saúde pública ligado a poluição industrial levaram a que vários governos começassem a responder de maneira mais sérias os problemas ambientais. Já setores da sociedade se organizam em torno de práticas que levassem em conta os efeitos da exploração humana em determinado com base em várias correntes filosóficas e éticas na interações entre homem e natureza. Deste choque surgiram um conjunto de práticas políticas que utilizaram o discurso da Sustentabilidade como pedra de toque principalmente a partir do relatório Brundtland (1987). Porém o largo uso do termo fez que o mesmo fosse definido de diferentes maneiras em relação ao grupo político que dele se utiliza.

SATO \& SANTOS, 1999 discutem que estas diferentes contradições concentram-se no contraponto do "crescimento quantitativo" contra o "desenvolvimento qualitativo". Outro ponto importante da interpretação destas políticas se dá no embate entre os países ricos do norte e os países pobres do Sul. As políticas do Norte são de um grande discurso sobre sustentabilidade, pressionados pelas seus eleitores e organizações sociais, e uma práxis voltada a manter as relações de compra de matéria prima barata do Sul, que é onde se baseia a sua prosperidade, além da relutância em diminuir os níveis de consumo de recursos. Já o sul, detentor de grande biodiversidade, caminha no fio da navalha de conciliar uma política de sustentabilidade com grande níveis de pobreza e uma profunda remessa de riquezas para os países do Norte. Este dilema faz com que os discursos de ambientalistas destes dois lados do mundo tenham palavras parecidas com usos e profundidades distintas (SCHLINDWEIN, 2009).

No âmbito dos sistemas produtivos individuais, das comunidades e das organizações representativas da agricultura familiar camponesa. A agricultura sustentável aqui se define como aquela que incorpora a conservação e manejo dos recursos naturais e os atores sociais envolvidos dentro da manutenção das propriedades ecológicas do sistema e da qualidade de vida dos camponeses. Em uma agricultura sustentável os sistemas tendem a manter sua alta diversidade e complexidade natural e cultural (ALTIERI, 1994; GLIESSMAN, 2000). O objetivo fundamental do desenvolvimento humano integral se ancora nos valores éticos, sociais, culturais e 
políticos, na dignidade do ser humano e na sua relação em sociedade. Com a presente ação a UFSCar visa atender a demanda de formação superior dos agricultores assentados pela Reforma Agrária e engajados com os movimentos sociais do campo. Um processo que se dará através de uma leitura atualizada e abrangente da relação sociedade - natureza e agricultura - meio ambiente, de suas implicações e dimensões sociais, econômicas, culturais e científico-tecnológicas. Busca-se formar profissionais com referências, elementos e conteúdos para atuar de forma ampla e qualificada, em prol do desenvolvimento rural sustentável, nas esferas tecnológica, social, ambiental, econômica e política.

\section{A PROBLEMÁtiCA DA AGRICULTURA CONVENCIONAL NOS TRÓPICOS}

As resistências, proposições e mobilizações dos movimentos sociais do campo estão em contraposição aos encaminhamentos vigentes da política econômica dominante, orientada pelo mercado liberal e baseada na capitalização do campo. A visão paradigmática do meio urbano como o espaço construído da civilidade, racionalidade e oportunidade, que contrapõe o meio rural como símbolo do atraso e das relações sociais brutas não só é falso, como também perverso. Os projetos de modernização do campo instituídos pelo estado brasileiro a partir da década de 1960 tiveram como expressões pacotes tecnológicos que não consideraram a diversidades de situações do território, desprezando a agricultura familiar camponesa. Mesmo as políticas agrícolas de operacionalização dos conhecimentos científicos adquiridos nos cursos superiores de Agronomia responderam em sua maioria apenas aos preceitos e demandas desta capitalização, encarando o mercado como finalidade e baseando-se em tecnologias exógenas.

O resultado deste processo é um profissional tecnicista, voltado atualmente ao agronegócio, monocultura e atividade predatória, incentivado pelo próprio estado brasileiro através do subsídio agrícola. Poucos são os esforços na formação de profissionais com um conteúdo técnico-científico que trabalhe com a perspectiva da construção de um novo modelo de desenvolvimento agrícola sustentável, no âmbito dos sistemas produtivos individualmente, das comunidades e das organizações representativas da agricultura familiar camponesa. 
A agricultura contemporânea está passando por uma crise sem precedentes, pois a forma pela qual tem sido orientada promove sérios impactos sociais e ambientais em âmbito mundial. O problema mais preocupante na realidade dos países periféricos, onde se inclui o Brasil, ocorre devido à transferência linear para as regiões tropicais e subtropicais de um padrão tecnológico com uso de capital intensivo, gerado para realidades temperadas e frias.

Dentre os problemas creditados ao setor agrícola estão o aumento da dependência e a perda de eficiência energética, o desmatamento e a perda de biodiversidade, a redução de variabilidade genética e susceptibilidade das espécies melhoradas para altas produtividades às pragas, doenças e estresses ambientais, a degradação dos recursos florísticos e edáficos pelo manejo inadequado, os desequilíbrios biológicos e ecológicos resultantes da monocultura e do uso de agroquímicos, a poluição do ambiente, dos alimentos e do ser humano por agrotóxicos, a concentração da terra, renda e meios de produção, com a desigual apropriação da riqueza gerada pelo setor.

Os impasses colocados à agricultura estão relacionados a razões de ordem cultural, econômica, política; e também à orientação científica e tecnológica que tem sido imprimida ao setor, em larga medida subordinada aos interesses do processo de acumulação capitalista do segmento agroindustrial.

A universidade fez parte deste processo. Organizou-se para gerar competências para modernizar e capitalizar o tempo e o espaço rural (UNEMAT, 2006). Este contexto acabou por marginalizar o pequeno agricultor do campo, reduziu a biodiversidade, promoveu a degradação ecológica e concentrou a renda da produção novamente entre as classes mais favorecidas pela política econômica vigente.

Tais lacunas e insuficiências têm motivado os cientistas a buscar novos entendimentos e concepções na investigação agronômica e na condução dos processos produtivos agrícolas, através de enfoques e métodos mais abrangentes, que propiciem o 
entendimento do todo, campo em que se insere a abordagem sistêmica, o holismo, a busca da inter e da transdisciplinaridade.

\section{BASES TEÓRICAS}

\section{A Agroecologia}

A Agroecologia pode dar uma expressiva contribuição, enquanto uma área da ciência que utiliza um referencial teórico e conceitual fundamentado na abordagem sistêmica, buscando entender e analisar a agricultura como um todo.

A agroecologia é definida como:

\footnotetext{
"A disciplina científica que enfoca o estudo da agricultura sob uma perspectiva ecológica e com um marco teórico cuja finalidade é analisar os processos agrícolas de forma abrangente. O enfoque agroecológico considera os ecossistemas agrícolas como as unidades fundamentais de estudo; e nestes sistemas, os ciclos minerais, as transformações de energia, os processos biológicos e as relações socioeconômicas são investigadas e analisadas como um todo" (ALTIERI \& NICHOLLS, 2000: 14).
}

A agroecologia lança mão do enfoque sistêmico no entendimento do funcionamento e na orientação das unidades produtivas, afora relevar os conhecimentos acumulados pelas populações locais, e seus processos de organização e gestão. Ela pressupõe a diversificação e a integração das atividades vegetais, animais e florestais, com a adequação da base genética ao meio, o que inclui a compatibilidade das espécies, raças, cultivares e variedades a cada situação ecológica.

Os sistemas produtivos orientados segundo os pressupostos da agroecologia geram impactos sociais e ambientais distintos do padrão convencional, o que pode vir a contribuir para a viabilização de formas sustentáveis da prática agrícola. Em tal esfera os agroecossistemas orientados com base nos princípios ecológicos estão, aparentemente, contribuindo para a redução e/ou superação de parte dos problemas ambientais, energéticos e sociais resultantes do padrão tecnológico dominante, através de métodos, 
técnicas e processos produtivos mais compatíveis com os objetivos de um modelo agrícola sustentável (ALTIERI \& NICHOLLS, 1989; GLIESSMAN, 2000).

Um comportamento ótimo dos sistemas de produção agrícola depende do nível de interações entre seus vários componentes, a conservação da biodiversidade, o restabelecimento do equilíbrio ecológico dos agroecossistemas para se alcançar uma produção sustentável (ALTIERI \& NICHOLLS, 1989).

Em relação aos sistemas naturais, os agroecossistemas se caracterizam por um limitado conjunto de propriedades dinâmicas que podem ser descritas não somente por seus comportamentos essenciais, mas que podem ser usadas normalmente como indicadores de sua performance, e desta forma, ser empregadas no planejamento e avaliação de projetos de desenvolvimento, em todos os níveis de intervenção.

Agroecossistemas podem ser considerados como verdadeiros sistemas cibernéticos $^{6}$, nos quais o objetivo é incrementar seu valor social. Isto é alcançado através de uma gama de estratégias que combinam diferentes níveis de produtividade, estabilidade, sustentabilidade e equidade.

Os processos ecológicos básicos - competição, herbivoria e predação permanecem válidos, mas eles são agora circunscritos e regulados por processos de cultivos agrícolas, subsídios, controles, colheitas e mercados. As reconhecidas metas dos sistemas aparentam estar reproduzindo a cooperação e a competição observada na sociedade humana e econômica. Sua consequiência é que o sistema adquire uma dimensão socioeconômica. Este novo sistema complexo agro-socioeconômicoecológico contemplando suas diversas dimensões é o que se denomina agroecossistema (CONWAY, 1987).

\section{O ENFOQUE SISTÊMICO}

Relativo ao processo de comunicação entre os sistemas tecnológicos, biológicos, sociológicos e econômicos. 
A investigação agrícola convencional lança mão do enfoque atomístico para estudar as técnicas e os processos inerentes à agricultura, tratando de forma compartimentada as questões relativas às plantas, aos animais, aos recursos edáficos, às variáveis econômico-financeiras, coerente como os paradigmas que orientam o pensamento científico contemporâneo a partir de Bacon, Descartes e Newton.

Conquanto um enfoque cartesiano na pesquisa seja necessário e adequado ao estudo de aspectos tópicos da produção, do manejo dos recursos naturais, da área socioeconômica, etc., ele tem se mostrado insuficiente à análise de processos mais amplos, caso daqueles abrangentes às esferas da produção agrícola e da circulação das mercadorias.

Nestes casos a alternativa é se utilizar uma abordagem analítica com um enfoque sistêmico, a qual permite correlacionar e analisar distintos campos, disciplinas e/ou variáveis envolvidas em determinado processo, podendo sua aplicação ser adotada na análise energética, ecológica, biológica, socioeconômica ou produtiva.

BECHT (1974) entende o sistema como um conjunto de componentes que formam e atuam com um todo. Tal conceito embute dois aspectos fundamentais a qualquer sistema que se pretenda estudar: sua estrutura e sua função.

A estrutura está relacionada com o arranjo dos componentes do sistema e a função com o como atua o sistema. A função de um sistema qualquer sempre se define em termos de processos, e está relacionada com o processo de receber entradas e produzir saída (HART, 1985).

A noção fundamental é a totalidade do sistema e também o complexo dos fatores físicos formando o que chamamos de bioma, em sentido lato os fatores do habitat. Os sistemas assim formados, do ponto de vista da ecologia, são as unidades básicas da natureza na superfície terrestre.

BIODIVERSIDADE E AGROBIODIVERSIDADE 
A biodiversidade é inerente à dinâmica evolucionária, em que mutação, recombinação genética e seleção natural combinam-se para produzir variabilidade, inovação e diferenciação na biota terrestre. A diversidade conduz a uma diferenciação de habitat, ao aumento da produtividade e reforça sua auto-reprodução, mantendo um papel importante na manutenção da estrutura e função dos ecossistemas.

Assumido o ecossistema como a unidade estrutural e funcional básica da natureza, verifica-se que o processo de sucessão ecológica é contínuo naquilo que poderia se chamar de equilíbrio dinâmico e que está associado à sua estabilidade, tanto maior quanto mais próximo do seu estádio de clímax. Uma maior complexidade do ecossistema tende a torná-lo mais estável, ou seja, a estabilidade aumenta proporcionalmente ao aumento do número de ligações tróficas nas teias alimentares. A maior diversidade resulta em uma maior resiliência do sistema ao impacto das forças externas (PASCHOAL, 1979).

Quando um ecossistema é perturbado cada uma das dimensões ecológicas de sua diversidade é simplificada, ou retrocede a um estágio mais primitivo de desenvolvimento. Reduz-se o número de espécies, diminui a estratificação vertical e ocorrem menos interações. Após a perturbação o ecossistema inicia o processo de recuperação, se restaurando a diversidade de espécies, as interações e os processos existentes antes da perturbação. O sistema alcança a maturidade quando o potencial pleno de fluxo de energia, de ciclagem de nutrientes e de dinâmica populacional pode ocorrer (GLIESSMAN, 2000).

Nos sistemas agrícolas a biodiversidade cumpre funções que vão além da produção de alimentos, fibras, combustíveis e renda. Tem influência na reciclagem de nutrientes, controle do micro clima, regulação de processos hidrológicos locais, regulação de organismos indesejáveis, desintoxicação de resíduos químicos nocivos (ALTIERI \& NICHOLLS, 2000).

Os métodos tradicionais de produção estão geralmente organizados para resistir a estresses ambientais e restrições de mão-de-obra, aproveitam o potencial da consorciação simbiótica de culturas, atendem às exigências dietéticas de populações, que lançam mão de 
métodos diferenciados em razão das características e disponibilidade de recursos. A diversificação de cultivos exibe um rol de características desejáveis de estabilidade socioeconômica, elasticidade biológica e produtividade.

A artificialização e a simplificação dos agroecossistemas foram aceleradas com o advento da agricultura industrial, em contraposição à lógica da agricultura tradicional. As extensas monoculturas, compostas geralmente de plantas geneticamente similares ou idênticas, que têm sido selecionadas por sua maior palatabilidade, são altamente vulneráveis a herbívoros adaptados.

Práticas agrícolas comumente usadas no manejo dos monocultivos (pesticidas, fertilizantes, químicos, etc.) tendem a alterar as populações de inimigos naturais dos herbívoros, desencadeando, assim, frequientemente os problemas de pragas (PAPAVIZAZ, 1981; ALTIERI \& NICHOLLS, 2000).

A estabilidade ecológica inerente e a auto-regulação podem ser reparadas restituindo os elementos homeostáticos perdidos na comunidade através da adição ou pelo incremento da biodiversidade funcional nos agroecossistemas. A biodiversidade se presta a uma grande variedade de serviços ecológicos, dentre eles a regulação da abundância de organismos indesejáveis através da predação, do parasitismo e da competição. Provavelmente, cada população de insetos na natureza é em alguma medida atacada por um ou mais inimigos naturais. Assim, predadores, parasitóides e patógenos atuam como agentes de controle natural e, quando adequadamente manejados, podem determinar a regulação de herbívoros em um agroecossistema particular. Tal regulação tem sido chamada de controle biológico e foi definida por De Bach (1964) como "a ação de parasitóides, predadores ou patógenos para manter a densidade da população de um organismo praga em um nível menor do que ocorreria em sua ausência" (ALTIERI \& NICHOLLS, 2000, P 149 )

Em essência, um comportamento adequado dos sistemas agrícolas depende do nível de interações entre seus vários componentes. A agroecologia provê as bases ecológicas para a conservação da biodiversidade na agricultura, além do papel que pode ter no restabelecimento do equilíbrio ecológico dos agroecossistemas, de forma a alcançar uma produção sustentável (ALTIERI \& NICHOLLS, 1989). 


\section{A Agricultura e SeU Impacto Sócio-Ambiental}

Em uma conjuntura em que a degradação sócio-ambiental tornou-se evidente, a preocupação com a sustentabilidade passou a ocupar lugar central nos debates contemporâneos, assim como a busca de alternativas que propiciem a superação das desigualdades sociais e da depleção dos recursos naturais.

A Agricultura se constitui na atividade antrópica que causa os maiores impactos negativos em âmbito espacial, e de distintas ordens.

O perfil da matriz energética da agricultura explicita parte da lógica e dos interesses que têm orientado o padrão tecnológico da moderna agricultura, em que uma de suas principais características é incrementar a dependência de energia externa, basicamente petróleo, derivados, e germoplasma crescentemente controlado pela iniciativa privada, em setores cada vez mais oligopolizados.

Como a dinâmica climática nas zonas tropicais e subtropicais determina solos ácidos e distróficos e uma elevada intemperização da fração da matéria orgânica, a opção por material genético exigente em fertilidade acarreta uma maior dependência da agricultura por fertilizantes de síntese. E por se constituir em material geralmente susceptível a pragas e doenças, tal orientação leva também à intensificação do uso de agrotóxicos.

O uso de agroquímicos, associado às monoculturas com variedades de reduzida variabilidade genética e elevada susceptibilidade a estresses ambientais promove desequilíbrios biológicos, agravando assim os problemas fitossanitários e realimentado a dependência do processo produtivo de elementos artificiais.

$\mathrm{Na}$ realidade brasileira o sistema educacional vigente, em geral, oferece uma formação profissional voltada ao atendimento de um mercado de trabalho determinado pelo padrão tecnológico hegemônico e pelos segmentos empresariais e comerciais 
colocados à montante e à jusante da produção primária, agora empenhados em ampliar a revolução verde através da engenharia genética e as espécies transgênicas.

Neste círculo vicioso os agricultores estão cada vez mais inseridos em um processo de relações de troca bastante desigual com os capitais industrial, comercial e financeiro, de forma subordinada, uma resultante do modelo tecnológico hegemônico, que amplia a dependência da agricultura de energia externa.

O potencial ambiental do desenvolvimento e as condições ecológicas de sustentabilidade levam a recolocar os problemas da dependência econômica e tecnológica dos países periféricos, estando os critérios da racionalidade ambiental a demandar uma reorientação das políticas científicas e tecnológicas para o aproveitamento sustentável dos recursos, visando a construção de estilos alternativos de desenvolvimento (LEFF, 2000).

\section{IMPACTOS DA MODERNIZAÇÃO AGRÍCOLA E AS ESCOLAS ALTERNATIVAS}

A partir do final da Segunda Guerra Mundial, e de forma mais expressiva com o advento da chamada "Revolução Verde", o setor produtivo agropecuário de muitos países sofreu transformações estruturais expressivas. Definimos "Revolução Verde" como um conjunto de técnicas agrícolas baseadas em uma intensa mecanização e usos de insumos químicos e combustíveis fósseis, baseada essencialmente na monocultura e na comercialização em grande escala. Tal orientação busca o aumento da produção e da produtividade através da manipulação genética e artificialização do processo produtivo pelo uso de agroquímicos (fertilizantes de síntese e agrotóxicos) e energia externa (SILVA, 1978), desprezando-se os saberes historicamente acumulados pelos agricultores, que adequaram seus sistemas produtivos a cada condição específica local, adaptando-os a condições adversas, através de um processo empírico de tentativas e erro, desenvolvendo sistemas de cultivo que permitiram o crescimento das populações e o desenvolvimento de sociedades complexas segundo a disponibilidade de recursos locais. 
No Brasil, nos últimos quarenta anos, o meio rural e as atividades e serviços que compõem a agricultura têm se vinculado de forma crescente aos complexos agroindustriais, com a agricultura perdendo autonomia. Concomitante ao incremento do Produto Interno Bruto (PIB) agrícola, da área cultivada, do volume da produção, e da produtividade de cultivos específicos, constata-se o incremento exponencial dos problemas ambientais, econômicos e sociais no meio rural.

Particularmente no âmbito da agricultura familiar, esses impactos foram expressivos: a concentração de renda, o desenvolvimento e expansão de tecnologias capital-intensivas inacessíveis a tal segmento, uma redução expressiva das ocupações no campo com a intensificação da mecanização nas fases dos processos produtivos, a queda do preço dos produtos recebido pelo agricultor e crescente endividamento. Situação que tem resultado na evasão da grande maioria dos jovens do meio rural.

Cientes e preocupados com esta realidade, há cerca de três décadas um número crescente de agricultores, técnicos, associações, cooperativas e Organizações NãoGovernamentais (ONG's) vêm buscando alternativas que viabilizem a permanência do homem no campo e a promoção da agricultura familiar camponesa, enquanto um segmento responsável pela manutenção de expressivo número das ocupações no meio rural (20 milhões contra 5 milhões na agricultura patronal e por boa parte da produção de alimentos destinados ao abastecimento interno (GUANZIROLI \& CARDIM, 2000).

Tais atores, desde o surgimento do movimento de agricultura alternativa nos anos 1970, passaram a desenvolver diversas iniciativas de produção orgânica e agroecológica, apoiados mais recentemente por organizações de consumidores, que buscam produtos saudáveis, de elevado valor biológico e sem resíduos de agrotóxicos.

No contexto dos movimentos de agricultura alternativa destacam-se as escolas de agricultura biodinâmica (KOEPF, 1983), biológica (AUBERT, 1977), natural (OKADA, 1982; FUKUOKA, 1985), orgânica (RODALE, 1983), permacultura ou agrossilvicultura (MOLLINSON \& HOLMGREN, 1983), que antecederam o surgimento da agroecologia (ALTIERI, 2000; GLIESSMAN, 2000). 
Em São Paulo e demais estados do Sudeste predominam sistemas orgânicos de produção voltados aos mercados interno e externo, dispersos por muitos municípios da Região. Observa-se, igualmente, que os paradigmas da agroecologia estão sendo crescentemente incorporados e aplicados pelos movimentos sociais ligados ao campo, e por algumas Universidades Públicas.

Por outro lado, a reforma agrária no Brasil atual não pode prescindir da formação de agricultores rurais camponeses, caracterizando-se apenas como uma política de acesso à terra, secundarizando a educação e a formação profissional. Esta é uma questão de especial importância, pois o fator educacional, a capacidade de empreender e gerir. Uma reforma agrária efetiva deve permitir que os agricultores rurais camponeses atinjam também a assim chamada economia do conhecimento. Ainda que isto possa ser tomado como tendência das economias modernas, o fato é que no Brasil a inclusão de significativas parcelas de populações marginalizadas no meio rural passa necessariamente pelo acesso à terra e à educação, constituindo-se em políticas eficazes de promoção da justiça social.

\section{Agricutura e Sustentabilidade}

\section{A ReorganizaÇão das Estratégias de ProduÇão}

A agricultura familiar tem grande importância no cenário socioeconômico brasileiro, tanto por sua capacidade de geração de postos de trabalho, como por sua capacidade de produção, especialmente de alimentos básicos. No início desta década cerca de $85 \%$ das propriedades rurais do Brasil pertenciam a grupos familiares. Existiam mais de 4,5 milhões de estabelecimentos agrícolas familiares no país, envolvendo um universo de 13,8 milhões de pessoas, que eram responsáveis por mais de $60 \%$ dos alimentos consumidos no país, empregando $77 \%$ do total de pessoal ocupado na agricultura e responsável por $38 \%$ do valor bruto da produção agropecuária nacional (GUANZIROLI \& CARDIM, 2000).

Quanto à multifuncionalidade da agricultura, apesar de muito estudada e apoiada pelas políticas públicas dos países mais desenvolvidos, carece de uma atenção adequada 
no Brasil. O conceito de multifuncionalidade implica dar atenção a outros fatores, como a dinâmica socioeconômica do mundo rural, com destaque para outras funções da agricultura, além do aspecto meramente agrícola. Assim, deve-se considerar a pluriatividade das famílias, as tecnologias organizacionais e de gestão, a organização da produção, as questões ligadas ao papel da agricultura familiar camponesa na segurança alimentar, na coesão social local, na preservação ambiental, na biodiversidade, na paisagem natural e na herança cultural. A noção de multifuncionalidade estabelece a ligação entre atividade agrícola e território, ao levar em conta a articulação da agricultura com o desenvolvimento local, seu papel de manutenção do emprego nas zonas rurais e os mecanismos que o setor agrícola oferece ao desenvolvimento dos territórios rurais. Os Territórios Rurais (MDA, 2008) são caracterizados por uma visão integradora dos espaços, atores sociais, mercados e políticas públicas, atingido as dimensões Ambiental, Sócio-cultural, Econômica e Político Institucional. Em suma, a função da agricultura não se limita simplesmente à produção de alimentos e matérias primas, devendo contribuir para um melhor equilíbrio social, territorial e ambiental (MALUF, 2001).

Se de um lado a agricultura convencional tende a reproduzir a insustentabilidade, por outro, os assentamentos de reforma agrária que não redefinirem suas estratégias de organização da produção estarão caminhando nesta mesma direção. Isto reforça a necessidade de uma política educacional voltada para a qualificação específica em agroecologia e sistemas rurais sustentáveis.

Com a comprovação da insustentabilidade do padrão tecnológico atual, novos marcos conceituais e operacionais passaram a ser construídos, visando melhor clarear e fundamentar propostas que apontem para a consecução de processos de produção agrícola sustentáveis. Tal construção tem ocorrido na esfera dos conceitos, das diretrizes, dos objetivos, dos princípios, buscando abranger as dimensões social, ecológica, energética e econômica da sustentabilidade (ALTIERI \& NICHOLLS, 1989).

A busca de processos de produção que apontem para a sustentabilidade é uma questão ampla e complexa, que perpassa a esfera dos valores, da cultura, da realidade física 
e demográfica, da orientação científica e tecnológica, das relações socioeconômicas e de poder entre os distintos segmentos e classes sociais.

Em um grande número de situações, a orientação das políticas públicas em última instância tem sido estabelecida de forma a atender aos interesses dos grupos hegemônicos nos espaços político e econômico, principalmente na ausência de organização e pressão social expressivas em prol dos interesses coletivos.

A consecução de uma produção agrícola sustentável é função de um balanço apropriado dos solos, cultivos, nutrientes, luz solar, umidade e dos sinergismos entre os organismos existentes. Quando este balanço e condições ótimas prevalecem, as plantas cultivadas são resistentes para tolerar o estresse e a adversidade.

Entende-se, assim, ser possível a consecução de padrões de produção afins aos pressupostos da sustentabilidade, desde que adotados processos e práticas compatíveis com os princípios ecológicos e a conservação dos recursos naturais, através de métodos de produção centrados na busca da auto-suficiência e da eficiência energética, e que prescindam dos agroquímicos potencialmente agressivos ao ambiente e ao ser humano.

\section{As Dimensões da Sustentabilidade}

A sustentabilidade na agricultura envolve pelo menos quatro dimensões: ecológica, econômica, social e energética (ALTIERI \& NICHOLLS, 1989).

No âmbito da ecologia a agricultura se constitui em uma atividade de caráter eminentemente biológico, complexo, determinado por uma série de relações entre o meio biótico e abiótico, entre os distintos níveis tróficos, entre o mundo vegetal e animal e microbiano (ressaltando interações micro-organismo-plantas).

De uma perspectiva ecológica, sistemas produtivos especializados com monoculturas não apresentam uma estrutura integrada entre seus componentes (solo, cultivos, animais); os ciclos de energia, nutrientes, água e resíduos são muito abertos 
(com muitas perdas). Muitos cultivos são conduzidos em condições marginais, demandando um maior uso de agroquímicos, energia não renovável de grande impacto ambiental; e uma permanente troca de germoplasma afeta a estabilidade biológica e produtiva do sistema no tempo (ALTIERI \& NICHOLLS, 1989).

Sob a ótica da economia clássica formal, a questão central do processo produtivo agrícola é seu resultado financeiro e o lucro auferido, buscado via incremento da produtividade do trabalho pela adoção de tecnologias capital-intensivas e poupadoras de mão-de-obra, cujos processos crescentemente mecanizados e automatizados promovem acentuada redução das ocupações no meio rural, concomitante à crescente capitalização da agricultura.

$\mathrm{Na}$ abordagem do agronegócio não são relevadas as "externalidades" da agricultura, e sob tal ótica o PIB agrícola embute uma distorção básica, na medida em que mede os bens criados, mas não deduz os custos sócio-ambientais resultantes de tal atividade antrópica.

Mas a dimensão sócio-econômica da sustentabilidade não se restringe apenas à viabilidade econômica e financeira da agricultura, ao tamanho do negócio agrícola, ou aos indicadores de pessoas ocupadas e consumo de insumos, como o considera a análise convencional.

Nesta esfera, afora a viabilidade material da agricultura, estão implícitas as questões afetas ao emprego, à sua qualidade e à sua manutenção no tempo; incorpora as questões de distribuição da renda agrícola face aos demais setores da economia; o como se dá a apropriação do lucro entre as agroindústrias, os agricultores e os trabalhadores rurais; assim como os benefícios sociais e materiais que estão ou não acessíveis àqueles que moram no meio rural, dentre outros aspectos.

Na esfera sócio-econômica a crise agrícola tem dimensão universal, em função da redução da renda dos agricultores no tempo, a qual é crescentemente apropriada pelos setores comerciais e industriais situados antes e depois da produção primária (SILVA, 1978, 1982; SMITH, 1992; COSTA, 2004). 
Nos países periféricos os efeitos da revolução verde em muitas situações foram catastróficos, dada a densidade populacional, desemprego crônico, descapitalização e endividamento dos agricultores. A nova orientação promoveu uma enorme migração rural urbana, pobreza e penetração do capital estrangeiro nestas agriculturas (ROSSET, 1999).

As desigualdades sociais, espaciais e temporais no uso dos recursos e serviços da natureza, sem a compensação com uma maior igualdade na distribuição econômica, têm levado ao surgimento de escolas que se contrapõem à economia neoclássica, dentre elas a economia ambiental, a economia ecológica (SUNKEL, 1998; ALLIER, 1998), e mais recentemente a economia solidária (SINGER \& SOUZA, 2000).

Em sua dimensão energética o padrão tecnológico agrícola tem evoluído de sistemas de mão-de-obra intensivos para processos crescentemente artificializados e mecanizados, obedecendo à lógica capitalista de incremento do consumo de energia e insumos industriais, e de aumento da produtividade do trabalho. Sob a ótica energética, todavia, tal evolução tem redundado em processos crescentemente ineficientes.

A maioria das pesquisas realizadas sobre a eficiência energética da agricultura tem comprovado que ela tem declinado, pois os crescentes aportes energéticos em insumos têm suplantado os acréscimos de energia resultantes da maior produtividade, afora a crescente insustentabilidade do processo, pois os aportes biológicos de energia renovável têm se reduzido (trabalho humano, animal e estercos), em prol dos aportes industriais (mecanização e agroquímicos), forma de energia não renovável (PIMENTEL et al., 1982; CASTANHO FILHO \& CHABARIBERI, 1982; DOERING, 1977).

A energia demandada pela agricultura é em larga medida oriunda do petróleo (combustíveis, lubrificantes, fertilizantes nitrogenados e agrotóxicos), o que clareia as razões para a pressão política e o investimento do complexo industrial na modernização da agricultura dos países do Hemisfério Sul (PIMENTEL et al., 1982, CASTANHO FILHO \& CHABARIBERI, 1982). Em síntese, a agricultura convencional usa hoje mais energia do que a energia que o alimento contém em si, e a maior parte da energia investida provêm de fontes finitas. 


\section{BASES MetodolÓgicas}

\section{MARCo CONCEITUAL}

A agronomia se constitui em um campo profissional de grande abrangência e complexidade, por tratar-se de um setor da atividade antrópica que se relaciona com praticamente todos os demais segmentos da economia. Tem uma relação direta com a base de recursos naturais que suportam a atividade, e sua condução envolve distintas áreas do conhecimento humano, nas esferas da ciência, da tecnologia, da economia e da política.

A presente proposta se articulou em torno de eixos orientados segundo um marco conceitual que busca enfocar a complexidade da ciência agronômica, em suas dimensões, de forma articulada e integrada. Um dos eixos do curso ora proposto é relativo à dimensão da atividade produtiva propriamente dita, abrangente às questões relativas à produção vegetal e animal, à fitotecnia e à zootécnica, às ciências florestais, e seus rebatimentos econômicos e sociais, enquanto um agroecossistema em sua dimensão agrosilvipastoril. Tratar-se-á da abordagem da orientação e condução possíveis de serem assumidas e adotadas segundo cada realidade ecológica e sócioeconômica. Outro eixo do curso diz respeito à relação do processo produtivo com a base de recursos que dão suporte à atividade, no que se caracteriza como as relações infrasistema produtivo, que abarcam todos os conteúdos relativos ao solo, flora e água, suas características, aptidões, limitações, manejo e conservação, dentro das reflexões a partir da tríade produção - cidadania - pesquisa (MICHELOTTI, 2008).

A construção do curso teve como objetivo formar um profissional que deverá ter embasamento técnico, humano, político e metodológico, adequado aos interesses da agricultura familiar camponesa que leve à compreensão de um desenvolvimento territorial em sua totalidade - política, social, cultural, ambiental e econômica (HACKBART, 2008). Em essência, a formação de um profissional capaz de planejar e executar um manejo adequado dos sistemas agrícolas, utilizando como base teórica os 
pressupostos da agroecologia, viabilizando os assentamentos em todos os seus elementos sócio-econômicos-ambientais.

No âmbito das relações supra-sistema o curso abordará as questões afetas ao clima, às dimensões política, sociológica e cultural da produção primária, os determinantes mercadológicos e infra-estruturais.

O tratamento dos aspectos produtivos propriamente ditos será realizado de forma articulada com as relações do agroecossistema à sua jusante e à montante. A produção cabe ser discutida de forma articulada com o padrão tecnológico, o grau de dependência do sistema de energia externa, aí entendidos: o germoplasma, agroquímicos, combustíveis e lubrificantes e energia elétrica, afora o tipo de informação recebida, as demandas de trabalho e recursos financeiros externos.

Considerando a cadeia produtiva, o agroecossistema será discutido à luz das suas relações, à jusante, com os demais atores. Situa-se nessa esfera o como a produção é colocada no mercado, se in natura ou processada, com que qualidade, para que tipo de mercado e consumidor.

Em face às experiências históricas, serão discutidas as relações de integração e de subordinação da produção agrícola ao processo de acumulação capitalista na esfera agroindustrial, comercial e financeira, na perspectiva de construir alternativas de desenvolvimento local através da organização de cadeias produtivas solidárias, cujos elos estratégicos (produção, processamento industrial, transporte e comercialização) estejam sob controle da agricultura familiar e suas organizações.

As distintas áreas do conhecimento humano, das ciências, com seus distintos matizes, especificidades e orientações, fundamentarão os conteúdos tratados durante o processo da formação profissional, aqui subentendidos os campos específicos das diferentes áreas de conhecimento, subsidiando a abordagem das questões mais amplas envolvidas na relação sociedade - natureza e da agricultura - recursos naturais.

Ao integrar os conteúdos das ciências exatas, sociais e biológicas, serão abordadas as dimensões das relações sociais de produção: cooperação, competição, 
produção individual, produção coletiva, organização taylorista do trabalho, organização cooperativa do trabalho, entre outras. Este processo de construção do conhecimento cujo método é também dialético possibilita a compreensão das contradições inerentes ao modo de produção capitalista.

O quadro delineado, representado no esquema que segue, apresenta as referências conceituais para a construção do presente projeto pedagógico (Figura 01).

Figura 1. Marco conceitual do projeto pedagógico para o Curso de Agronomia com ênfase em Agroecologia e Sistemas Rurais Sustentáveis proposto pelo GT INCRAPRONERA/UFSCar.

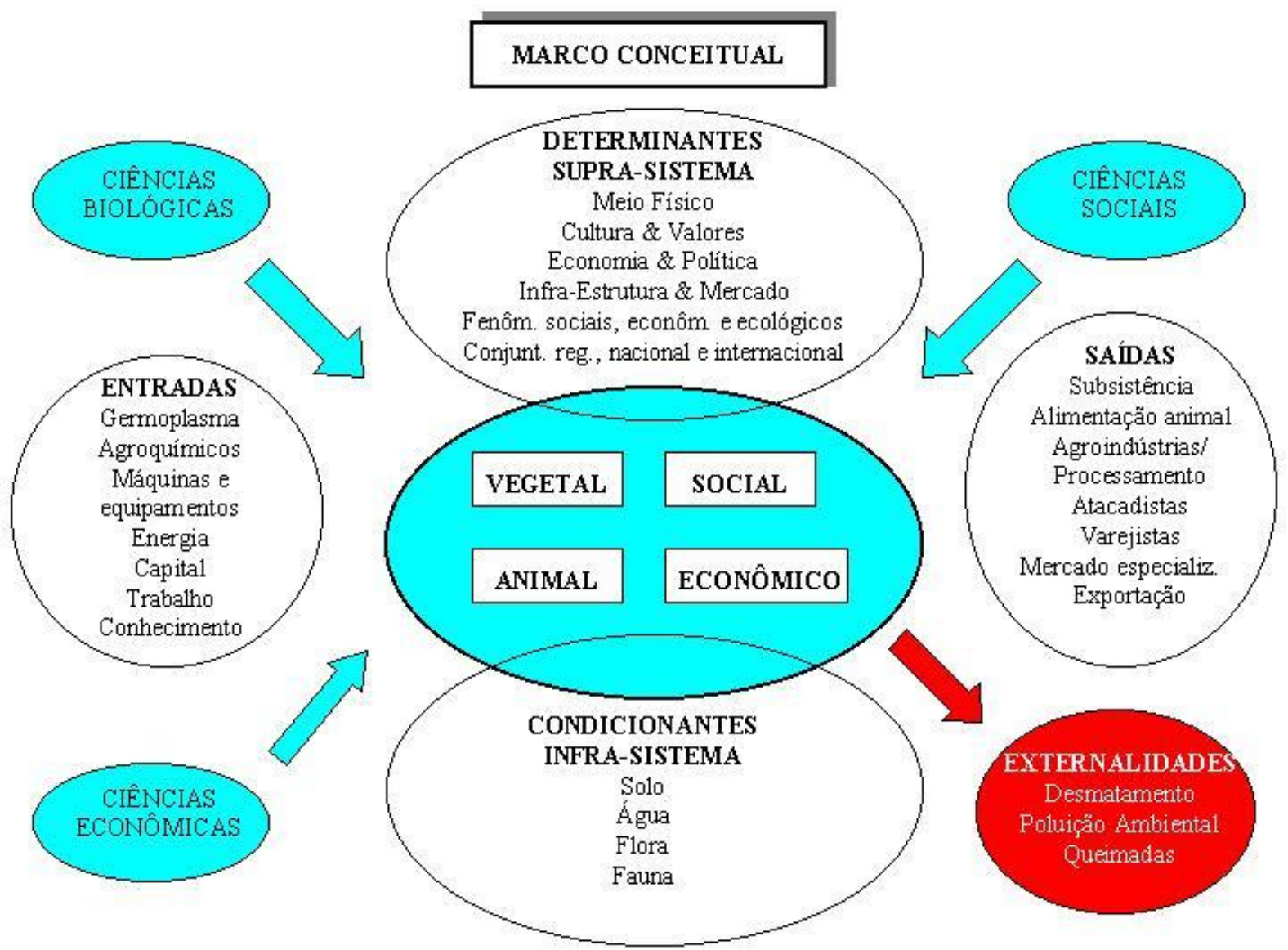


Entende-se a viabilidade e a sustentabilidade da agricultura familiar camponesa intrinsecamente relacionada ao desenvolvimento do entorno, relevando-se sua diversidade e complexidade social, cultural, econômica, ambiental, tecnológica, energética, dentre outras, materializadas nas relações antrópicas produtivas, de transformação e comercialização.

Adota-se como marco teórico e conceitual a agroecologia, o que pressupõe uma visão sistêmica e uma abordagem multidisciplinar do conhecimento focado na sua totalidade e complexidade de suas relações. Estabelecendo pontes tanto entre os diferentes campos do conhecimento, como entre os diferentes seres que compõem a coletividade, de forma distinta do tratamento de conteúdos segundo disciplinas isoladas. Evita-se adotar a dinâmica "aulas teóricas e aulas práticas" porque se entende que toda teoria está vinculada a práticas, e não há prática sem teoria.

\section{Marco Metodológico}

A proposta metodológica deste curso se fundamenta numa abordagem construtivista, que considera todos os participantes de um processo pedagógico como sujeitos atuantes, que têm conhecimentos, são capazes e se educam mutuamente. Embora com papéis específicos e diferenciados professores, estudantes, organizações ou comunidades educam-se num processo coletivo de construção, troca e aquisição de conhecimentos, a partir do que cada um já sabe e do conhecimento científico já sistematizado, em diálogo com as práticas cotidianas dos próprios sujeitos.

Em todos os tempos e espaços serão envidados esforços na concretização de uma abordagem na qual os diversos conhecimentos dialoguem e os sujeitos qualifiquem sua práxis. Embora tenham características específicas e próprias, estes tempos e espaços estão inter-relacionados e têm um papel importante no desenvolvimento de projetos que contribuam para a evolução individual e social do estudante, que se condicionam mutuamente, assim como de suas comunidades de origem. 
Além das atividades presenciais o estudante desenvolverá, sempre mediante orientação, diagnósticos, pesquisas, elaboração e execução de projetos em sua propriedade e/ou comunidade, no que serão orientados, acompanhados e avaliados pelos professores, monitores e colaboradores da iniciativa.

O curso possibilitará aos participantes estudar, pesquisar e desenvolver projetos e práticas que lhes permitam o domínio de fundamentos, princípios e bases científicas seguras para atuarem em diferentes instâncias: nos sistemas produtivos, nas comunidades e em organizações da agricultura familiar camponesa (grupos, associações, cooperativas, sindicatos) e no campo das políticas públicas.

Visando atingir o perfil profissional desejado, este projeto adota uma estrutura curricular que viabiliza uma relação permanente entre instituição de ensino, educando e comunidade, articulando e valorizando o saber acadêmico historicamente acumulado com o saber popular e empírico dos sujeitos locais.

Com base nesta concepção, é fundamental que as áreas de conhecimento se integrem numa perspectiva interdisciplinar, superando a fragmentação entre os saberes científicos e técnicos e os saberes voltados para a construção de novos valores e relações humanas.

Cabe destacar que o ponto de partida da construção do conhecimento pretendido neste curso é a realidade, as situações próximas das pessoas, dos educandos, seus contextos sócio-econômicos e culturais, suas formas de organização, de produção e de inserção no mercado. Procurar-se-á inverter neste processo, aquilo que é a marca mais acentuada da formação acadêmica tradicional: partir da teoria, numa estrutura disciplinar a partir de pré-requisitos para se chegar finalmente à prática.

As ações de ensino serão trabalhadas na perspectiva da interdisciplinaridade, articuladas com as atividades de pesquisa e extensão, numa concepção de construção do conhecimento em "rede", onde a disciplina é um ponto constitutivo desta rede, não um fim em si mesmo. 
Uma estratégia a ser adotada, visando a integração de atividades de ensino, pesquisa e extensão, é o regime de alternância, no qual os educandos dedicarão parte de seu tempo escolar às atividades didáticas presenciais, e outra parte a trabalhos em seus agroecossistemas, e/ou junto à sua comunidade de origem, contemplando os aspectos produtivos, tecnológicos e político-organizacionais.

\section{Perfil Profissional}

A estruturação do presente curso segue coerente com as mudanças e o ritmo das sociedades contemporâneas. Neste sentido, o profissional deve ser capaz de aprender de forma autônoma e contínua, articulado com as fontes geradoras de pesquisas e informações.

O curso foi concebido de forma a garantir a formação de agrônomos com um perfil profissional que os habilite a analisar criticamente e a repensar as formas de interação da agricultura com a realidade em que esteja inserida, com ênfase no segmento da agricultura familiar camponesa, valorizando e contribuindo para a equidade na distribuição da renda, a valorização das culturas locais e o respeito ao meio ambiente. Este perfil destaca uma dimensão fortemente ética do agir profissional ao sinalizar que deve pautar-se na ética da solidariedade enquanto ser humano, cidadão e profissional, buscando maturidade, sensibilidade e equilíbrio ao agir profissionalmente. Trata-se de formar um profissional que não apenas atenda às demandas sócioprofissionais da sociedade brasileira, com ênfase nas áreas de reforma agrária, mas também caudatário de valores que estão na base da construção de uma sociedade democrática e mais justa. Como tal, deverá atuar tendo como horizonte maior de sua ação uma visão planetária de compromisso com a preservação da biodiversidade no ambiente natural e construído, com sustentabilidade e melhoria da qualidade de vida.

O profissional a ser formado deverá ter um embasamento técnico, humano, político e metodológico adequado para que atue na área da agronomia e da agroecologia em unidades familiares, comunidades, associações, cooperativas e esfera pública. 
Dentro do projeto o objetivo é fornecer ao educando saberes e práticas que o permitam:

- Planejar, organizar, monitorar e executar o manejo orgânico, conservacionista e sustentável dos solos;

- Planejar e executar o manejo dos fatores microclimáticos, hídricos e florísticos, segundo uma visão sistêmica da unidade produtiva rural, de suas relações com o entorno, e da sustentabilidade em suas dimensões ecológica, econômica, social e energética;

- Elaborar, aplicar e monitorar programas de processamento da produção animal, vegetal e agroindustrial de produtos agroecológicos, através de métodos profiláticos e higiênicos;

- Avaliar as etapas da cadeia produtiva visando sua sustentabilidade econômica, ambiental e social;

- Orientar e Viabilizar sistemas de cultivo mínimo e plantio direto agroecológico;

- Planejar e orientar a produção e a propagação de sementes e mudas em cultivos abertos e protegidos.

- Elaborar, monitorar e aplicar métodos naturais e alternativos de proteção das plantas às pragas, doenças e espécies invasoras;

- Planejar e orientar a nutrição e o manejo na produção animal com base na otimização do uso dos recursos endógenos à unidade produtiva rural;

- Compreender e orientar métodos e programas de reprodução animal;

- Viabilizar sistemas de controle de qualidade na produção agropecuária;

- Utilizar práticas e métodos alternativos de controle da sanidade animal;

- Elaborar, monitorar e aplicar métodos naturais, ecológicos e homeopáticos no controle de doenças, ecto e endoparasitas que afetam a produção animal;

- Atuar no melhoramento genético, seleção e reprodução de espécies e variedades vegetais e animais compatíveis com as distintas realidades edafoclimáticas e sócio-econômicas;

- Planejar, projetar, implantar, monitorar e gerenciar atividades agrícolas, em sua dimensão agrosilvipastoril;

- Orientar o uso de máquinas e equipamentos adaptados à agricultura familiar camponesa e ao manejo ecológico dos sistemas produtivos;

- Utilizar métodos e processos baseados em formas renováveis de energia no meio rural;

- Desencadear e animar processos participativos e democráticos de cooperação e organização para o desenvolvimento sustentável das unidades familiares de produção, associações, cooperativas, comunidades e municípios; 
- Contribuir na coordenação e execução de políticas públicas voltadas à agricultura familiar camponesa, à conservação dos recursos naturais e ao desenvolvimento rural sustentável;

- Interpretar e orientar a aplicação da legislação agropecuária e ambiental;

- Identificar e assessorar a aplicação das diferentes formas de organização econômica na esfera da distribuição e da comercialização de produtos agrícolas;

- Identificar as relações ecológicas entre os seres vivos e entre os seres vivos e o meio abiótico, planejando e executando práticas ambientais visando a sustentabilidade da propriedade rural;

- Elaborar e implantar projetos de instalações rurais, nas áreas de sua competência profissional;

- Interpretar a legislação e organizar processos de certificação de produtos orgânicos;

- Coordenar, elaborar e executar projetos florestais e de recuperação de áreas degradadas.

- Elaborar laudos, perícias, pareceres, relatórios e projetos agropecuários no âmbito de sua competência profissional.

Um dos elementos importantes neste projeto é contribuir para a articulação da Educação Profissional Superior com outras políticas públicas afins ao desenvolvimento sustentável no meio rural de todas as suas dimensões, contribuindo-se assim para geração de ocupações e renda no campo e a qualificação de quadros técnicos para atuar na esfera da Agronomia e do Desenvolvimento Rural Sustentável dos Assentamentos da Reforma Agrária. O curso tem como objetivo geral formar em nível de Graduação em Agronomia agricultores assentados em projetos de reforma agrária do Estado de São Paulo, reconhecidos pelo INCRA, com ênfase na agroecologia e sistemas rurais sustentáveis, em sua relação com o ambiente, produção, processamento, gestão e comercialização. Para isto foram propostas e amplamente discutidas uma matriz curricular que pudesse fornecer aos estudantes/assentados dentro deste perfil específico.

A discussão coletiva do projeto gerou uma proposta curricular, onde o fluxo das disciplinas articuladas em uma Matriz Integrativa, com duração de cinco anos distribuídos em dez períodos pelas áreas de conhecimento (AC) - Fundamentos Básicos (FB), Ciências Humanas (CH), Recursos Naturais (RN), Produção Animal, Vegetal e Agroecologia (PAVA), Engenharia Agrícola e Tecnologias (EAT) - e atividades integradoras. Adota-se o critério de 60 horas por disciplina, sendo 48 presenciais distribuídas em uma semana de atividade em sala de aula ou laboratório e 
complementadas por 12 horas-atividade, caracterizando o tempo-comunidade. As aulas presenciais ocorreram nos meses de janeiro, fevereiro e julho e o curso teve início em janeiro de 2009. O total de horas-aula do curso, incluindo 120 horas para Elaboração da Monografia e 240 horas de estágio é de 4.050 horas. Portanto, a aprovação no curso implica na realização de 270 créditos, cada crédito correspondendo a 15 horas-aula. Uma das características mais enfatizadas na metodologia proposta é a relação das disciplinas com a realidade local dos assentamentos. Este talvez seja o mais importante exercício a ser realizado por professores e estudantes dentro do curso: a capacidade de produzir diagnóstico e proposta de manejo dentro dos assentamentos a partir das disciplinas trabalhadas. Para atingir esta meta foi elaborado um processo permanente de avaliação do curso.

\section{Tempos e Espaços Didático - Pedagógicos}

Como estratégia pedagógica o projeto fará uso da Pedagogia da Alternância, tentando estabelecer o diálogo entre os conteúdos e práticas trabalhados nas disciplinas e o dia a dia do educando no assentamento. A evolução individual e a evolução social se condicionam mutuamente, aspecto fundamental da metodologia proposta é a garantia de atividades individuais, em pequenos grupos, e em grupos maiores, para estudo, elaboração, pesquisas e práticas. Estas atividades complementares são importantes à orientação desejada na construção e organização do conhecimento.

Os tempos e espaços coletivos possibilitam a troca, o debate, o contraditório, a interação, a cooperação, o exercício da liderança e da democracia.

Os tempos e espaços individuais possibilitam a reflexão e a observação de fenômenos de interesse particular, o desenvolvimento do potencial pessoal de cada um e o processo individual de sistematização e (re) organização dos conhecimentos, o que qualificará ainda mais sua participação no grupo e no projeto do curso, desencadeando um círculo virtuoso de aprendizagem. 
O papel do curso, neste sentido, é promover e orientar vivências individuais e grupais, garantindo a inter-relação entre os processos pessoais e coletivos em torno de um projeto pedagógico coerente, que respeite e valorize os acúmulos individuais e contribua na organização dos diversos conhecimentos do grupo, aprofundando-os, problematizando-os, ampliando-os e reelaborando-os quando necessário, a partir de sólidas bases de conhecimentos.

Estes tempos e espaços diferenciados visam, a um mesmo tempo, garantir o desenvolvimento da individualidade e da coletividade, desenvolvendo atitudes, conceitos e valores importantes para a atuação do futuro profissional que, desde seu ingresso no curso vivencia a experiência de ser um agente de desenvolvimento sustentável e de atuar cooperativamente, assumindo seu papel no grupo.

Além das atividades presenciais, o estudante será estimulado e orientado na realização de diagnósticos, pesquisas, elaboração e execução de projetos no assentamento, no que serão orientados, acompanhados e avaliados pelos professores, monitores e colaboradores da iniciativa. Criar-se-á condições necessárias para que professores acompanhem periodicamente os trabalhos dos educandos em seu tempocomunidade.

Dentro desta perspectiva, possibilitar-se-á uma relação mais permanente entre instituição de ensino, educando e comunidade, relacionando os saberes acadêmicos historicamente acumulados com os saberes populares dos sujeitos locais.

Assume-se também os diagnósticos como elemento que introduzirá o estudante na prática do planejamento e da gestão, aspecto que será abordado de forma recorrente no decorrer do curso.

\section{a - Tempo-espaço presencial}

Serão tempos e espaços privilegiados de estudo e aprofundamento bibliográfico, com tempos para estudos, leituras e pesquisas, e além das atividades pedagógicas. Em casos específicos serão realizadas e/ou acompanhadas práticas e experimentações. A 
depender das temáticas e conteúdos em pauta, serão organizados dias de campo e viagens de estudo.

\section{b - Tempo-espaço comunitário}

Estes tempos-comunidade estabelecerão uma ponte direta entre os estudos e a situação concreta dos assentamentos de reforma agrária onde residem os estudantes. Isso permite que os interesses e desafios reais do cotidiano da agricultura familiar camponesa se tornem objeto de estudo e teorização.

Os tempos e espaços num primeiro momento terão caráter de investigação, observação, convivência, diagnóstico e intercâmbio para, em um segundo momento, ser transformado em projetos de atuação e intervenção.

Dentre as atividades que poderão ser desenvolvidas nos assentamentos incluemse cursos, experimentação e validação tecnológica, seminários temáticos organizados pelos estudantes, com base em demandas concretas. Tais ações coletivas deverão ser articuladas com a coordenação do curso e assessoradas por professor com conhecimentos na área.

\section{c - Tempo-espaço individual}

Além da escola o estudante realizará diagnóstico, pesquisas, elaboração e execução de projetos em sua propriedade sob orientação, acompanhamento e avaliação dos professores e bolsistas que participem do projeto. A escola viabilizará este acompanhamento sistemático, criando as condições necessárias para que os professores se desloquem até as propriedades, periodicamente.

Outro aspecto fundamental destes projetos a serem desenvolvidos nos assentamentos é que eles são uma ponte de ligação do curso com a comunidade. Uma iniciativa pedagógica - a um só tempo de aprendizagem e de mudança concreta nos (sub) sistemas da unidade familiar - que pode provocar a curiosidade, o interesse e o debate com famílias da vizinhança e comunidades próximas, potencializando o impacto imediato do curso. 
Pela sua importância político-metodológica e técnica, a aceitação de bolsistas e seu papel no projeto serão definidos pela Coordenação Pedagógica. O estudante será orientado na utilização de métodos de pesquisa e desenvolvimento, exercitando-se primeiramente em projetos e sistemas menos complexos, sobre os problemas e desafios reais do cotidiano da agricultura familiar camponesa. Assim, num segundo momento poderão atuar com segurança em sistemas de maior abrangência e complexidade, inclusive em estudos e teorizações sobre a agricultura familiar camponesa.

Proceder-se-á à orientação, acompanhamento e avaliação das atividades e projetos desenvolvidos fora do espaço tempo-presencial, com um diálogo permanente entre o corpo docente e discente, coordenação e organizações participantes.

Quanto aos procedimentos de como vai se dar a organização do curso em si, na concepção e preparação dos trabalhos serão realizadas discussões coletivas, sobre os referenciais teóricos, aspectos metodológicos e operacionais a serem adotados. Esperase que as propostas resultantes dos trabalhos sejam concretas e factíveis à mitigação ou superação dos problemas de maior magnitude, que demandam ações mais imediatas em seu universo de vivência: propriedade e comunidade. Proceder-se-á ao acompanhamento dos trabalhos dos educando em seu tempo-comunidade, criando-se as condições necessárias para que os professores se desloquem até as propriedades, periodicamente.

Os projetos deverão estar estreitamente relacionados e articulados com os temas em desenvolvimento no curso, alimentadores do processo coletivo, gerando subsídios, informações e tecnologias que possam ser socializadas, analisadas e apropriadas coletivamente para a qualificação de todo o grupo e do próprio curso. Desta forma, em alguns momentos, os projetos individuais serão espaços de estudos coletivos da turma. O curso, através dos professores e juntamente com os estudantes, poderá organizar grupos de trabalho para elaboração e desenvolvimento de projetos em associações, grupos, comunidades e outras organizações como um estágio técnico-pedagógico. Excepcionalmente, algum estudante poderá desenvolver algum projeto comunitário individualmente. 


\section{CONSIDERAÇÕES FinAIS}

Espera-se com o curso que a realidade dos assentamentos e da agricultura familiar camponesa seja prioridade no estabelecimento dos processos de aprendizado. O modelo de agricultura a ser buscado e estudado nesta proposta estará voltado para a sustentabilidade dos agroecossistemas, inclusão social e viabilidade técnico-econômica das atividades agropecuárias. A intenção não é apenas que o assentado estabeleça bases técnico-científicas que garantam sua subsistência na obtenção de produtos "orgânicos", mas que possa ter autonomia em meio às pressões externas do mercado capitalista. Ele será um produtor agrícola diferenciado pela qualidade de seu sistema agroecológico de produção, e não um reprodutor de formas de relações sociais e econômicas que destroem as relações mútuas do convívio humano e ecológico.

A crença nos pressupostos político-pedagógicos do curso obviamente constitui o estímulo inicial para atuação dos educandos em suas realidades. Mas a vivência e compreensão dos problemas poderão ser apenas efetivadas em efetivos procedimentos de transformação da realidade ambiental e sócio-econômica se houver um realinhamento das expectativas cotidianas na realização ensino-aprendizado. O diálogo entre a prática pedagógica do curso e as realidades dos educandos, portanto, será fundamental para sua efetivação enquanto transformador das realidades dos assentamentos e da efetiva implementação de sistemas rurais sustentáveis nos assentamentos.

Por fim, a atuação interinstitucional deve, basicamente, funcionar. A coesão do Grupo de Trabalho tem resultado em um projeto sólido, e tal característica é necessária nos tempos-escola/comunidade que estão por vir. A chave para garantir esta atuação deve ter seus alicerces na expressão dos pressupostos didático-pedagógicos, na legitimidade das instituições envolvidas e na realidade respeitada dos camponeses. 


\section{REFERÊNCIAS BIBLIOGRÁFICAS}

ALLIER, J. M. Da economia ecológica ao ecologismo popular. Trad. Armando de Melo Lisboa. Blumenau: FURB, 1998. 402p.

ALTIERI, M. Bases Agroecologicas para uma produccion agricola sustentable. Agricultura Tecnica, Chile, v.54, n.4, Octubre/Diciembre, 1994. p.371-386.

ALTIERI, M.; NICHOLLS, C. Agroecologia: as bases científicas da agricultura alternativa. Trad. de Patrícia Vaz. Rio de Janeiro: PTA/FASE, 1989. 240p.

Agroecologia: teoría y práctica para una agricultura sustentable. México: PNUMA y Red de formación ambiental para América Latina y el Caribe, 2000. $250 \mathrm{p}$.

AUBERT, C. A industrialização da agricultura: salvação ou suicídio da humanidade? Porto, Portugal: Afrontamento.1977. 96p.

BECHT, G. Systems theory, the key to holism and reductionism. Bioscience, v.24, n.10, 1974. p. 579-596.

CASTANHO FILHO, E. P.; CHABARIBERI, D. Perfil energético da Agricultura Paulista. São Paulo: Instituto de Economia Agrícola, 1982. 55 p.

CONWAY, G. R. The Properties of Agroecosystems. In Agricultural Systems 24, 1987. p.97-117.

COSTA, M. B. B. Análise da Sustentabilidade da Agricultura da Região Metropolitana de Curitiba sob a Ótica da Agroecologia. Tese de Doutorado. Curitiba: UFPR, maio de 2004. 292 p.

DOERING III, O.C. An energy-based analysis of alternative production methods and cropping systems in Corn Belt. Purdue University, Agriculture Experimente Station, 1977.

FUKUOKA, M. Agricultura natural. Teoria e prática da filosofia verde. Trad. Hiroshi Seó e Ivna Wanderley Maia. São Paulo: Nobel, 1985. 300p.

GLIESSMAN, S. R. Agroecologia. Processos Ecológicos em Agricultura Sustentável. Trad. Maria José Guazzelli. Porto Alegre: UFRGS, 2000. 653p.

GUANZIROLI, C.E, CARDIM, S.E.C.S.. Novo retrato da agricultura familiar: o Brasil rescoberto. Brasília: Incra-FAO. 2000. 74p. 
HACKBART, R. Apresentação. In Por uma educação no campo. SANTOS, C. Brasília: MDA-INCRA. 2008.

MDA. Territórios da Cidadania. Brasília: MDA-INCRA. 2008.19p.

HART. R. D. Conceptos básicos sobre agroecossistemas. Turialba: CATIE, 1985. 160 p.

KOEPF, H. H.; PETERSSON, B. D.; SCHAUMANN,W. Agricultura biodinâmica. Trad. Andreas Lowens e Ursula Szajewski. São Paulo: Ed. Nobel, 1983. 333p.

LEFF, E. Saber Ambiental: Sustentabilidaqde, Racionalida, Complexidade, Poder. Petrópolis: Vozes:Pnuma. 2002. 343 p.

LEFF, E. Ecologia, capital e cultura: racionalidade ambiental, economia participativa e desenvolvimento sustentável. Trad.: Jorge Esteves da Silva. Blumenau: Ed. Da FURB, 2000, 275p.

MALUF, R. S. O enfoque da multifuncionalidade da agricultura: aspectos analíticos e questões de pesquisa. In Lima, D. M. A e Wilkinson, J. (orgs). Inovação nas tradições da Agricultura Familiar. Brasília (DF), CNPq/Paralelo 15, 2002.

MICHELOTTI, F. Educação no campo: reflexões a partir da tríade produção-cidadaniapesquisa. In Por uma educação no campo. SANTOS, C. Brasília: MDA-INCRA. 2008.

MOLLINSON, B.; HOLMGREN, D. Permacultura Um. São Paulo: Editora Ground, 1983.

OKADA, M. Introdução à Agricultura Natural. São Paulo: Fundação Mokiti Okada, 1982. $65 \mathrm{p}$.

PAPAVIZAZ, G. C. Biological control in crop production. Beltsville Symposia in Agricultural Research. Allanheld, Osmun Pub. Oondon, 1981.461p.

PASCHOAL, A. D. Pragas, praguicidas \& crise ambiental: problemas e soluções. Rio de Janeiro: Fundação Getúlio Vargas, 1979. 106p.

PIMENTEL, D. et al. Produção de alimentos e Crise energética. Trad. Tania M. C. Bianchini e Rev. Oswaldo C. Rockenback e Paulo S. Tagliari. Florianópolis: EMPASC, 1982. 24p. (EMPASC - Documentos, 14).

RODALE, R. Braking new ground: the search for a sustainable agriculture, Futurist (1), 1983. pp. 15-20. 
ROSSET, P. M. Input substitution: a dangerous trend in sustainable agriculture. In: Workshop sobre Agroecologia e Desenvolvimento Sustentável. Coletânea de textos. Campinas: Unicamp; Instituto de Biologia, 1999. V.1.

SATO, M.; SANTOS, J.E. Agenda 21 em sinopse. Editora Ufscar. 60p. 1999.

SCHLINDWEIN, M.N. Fundamentos de Ecologia para o Turismo:introdução aos conceitos básicos em Ecologia para o planejamento de atividades turísticas sustentável. São Carlos: Edusfcar. 2009. 100p.

SILVA, J. F. G. (Coord.). Estrutura agrária e produção de subsistência na agricultura brasileira. São Paulo: Hucitec, 1978. 267p.

A modernização dolorosa. Estrutura agrária, fronteira agrícola $e$ trabalhadores rurais no Brasil. Rio de Janeiro: Zahar, 1982. 192p.

SINGER, P.; SOUZA, A. R. (Orgs). A Economia Solidária no Brasil: a auto-gestão como resposta ao desemprego. São Paulo: Contexto, 2000. 360 p.

SMITH, S. Farming. It's declining in the U.S. Choices, v.7, 1992. pp.8-10.

SMITH, J., ENGLER, E. Environmental Sciences. Cambridge: Cambridge University Press. 1995.

SUNKEL, O. Conferência. DESENVOLVIMENTO E MEIO AMBIENTE NO BRASIL. Porto Alegre: Pallotii. 1998. p.45-63. 448p.

UFSCAR - Universidade Federal de São Carlos. Curso Especial de Bacharelado Agronomia com Ênfase em Agroecologia e Sistemas Rurais Sustentáveis: Proposta de Projeto Pedagógico. INCRA-PRONERA/UFSCar, 2008. 72p.

UNEMAT - Universidade do Estado do Mato Grosso. Projeto Acadêmico: Curso de Agronomia dos Movimentos Sociais do Campo - CAMOSC. Cáceres: UNEMAT, 2006. 89 p. 